\title{
Comparative Cross-Sectional Pharmacovigilance Study of Medication Errors in Children and Adults in Community-Based Hospitals
}

Jimenez $\mathrm{A}^{1,2}$, Tran $\mathrm{TM}^{3}$, Le B ${ }^{4}$, Le $\mathrm{J}^{4^{*}}$

${ }^{1}$ Providence Little Company of Mary Medical Center, Torrance, CA

${ }^{2}$ Miller Children's and Women's Hospital, Long Beach, CA

${ }^{3}$ University of California Riverside, School of Medicine, Riverside, CA

${ }^{4}$ University of California San Diego, Skaggs School of Pharmacy and Pharmaceutical Sciences, La Jolla, CA

Corresponding Author: Jennifer Le, PharmD, MAS, FCCP, BCPS-ID

Address: Professor of Clinical Pharmacy, University of California San Diego, Skaggs School of Pharmacy and Pharmaceutical Sciences, 950o Gilman Drive, MC 0657, La Jolla, CA, 92093-0657; Phone: (858) 534-3692; Fax: (858) 822-6857; Email: jenle@ucsd.edu

Received date: 12 January 2020; Accepted date: 23 January 2020; Published date: 29 January 2020

Citation: Jimenez A, Tran TM, Le B, Le J. Comparative Cross-Sectional Pharmacovigilance Study of Medication Errors in Children and Adults in Community-Based Hospitals. Asp J Pediatrics Child Health. 2020 Jan 29;2(1):1-12.

Copyright (C) 2020 Jimenez A, Tran TM, Le B, Le J. This is an open-access article distributed under the Creative Commons Attribution License, which permits unrestricted use, distribution, and reproduction in any medium provided the original work is properly cited.

\begin{abstract}
Objective: To compare medication errors that reached pediatric and adult patients during hospitalization.

Methods: Observational, non-experimental, cross-sectional study from January 2011 to March 2015 at two community-based, teaching hospitals.

Results: Over a 4-year period, there were 4.2 and 13.3 million doses dispensed in pediatrics and adults, respectively. Less than $0.25 \%$ of doses dispensed contributed to medication errors, with $9.6 \%$ of these medication errors reaching patients and $0.04 \%$ causing harm. There was no statistical difference in medication error rates based on doses dispensed, patient-days, admission rate, and severity. However, significantly more errors in the documentation and prescribing processes occurred in adults (21.9\% vs $6.5 \%$ and $37.4 \%$ vs $29.8 \%$ respectively, $\mathrm{p}<.001$ ) versus administration in pediatrics ( 42.5 vs $29.8 \%$ in adults, $\mathrm{p}<0.001$ ). Errors in drug administration that occurred in pediatrics consisted of infusion devices, incorrect dose, the omission of medication, and time of administration. Pediatrics had higher medication errors related to electrolytes and total parenteral nutrition. Independent of age, there were more medication errors that caused harm in patients residing in the intensive care unit (5.5\% of 769 vs $3.5 \%$ of 2800 patients, respectively, $\mathrm{p}=0.006$ ).

Conclusion: While the prevalence of medication errors that reached patients and caused harm were similar between adults and pediatrics, the types of errors within the medication use process, class of drugs, and severity of the mediation errors varied between the groups. Given these differences, it is quintessential to develop population-specific medication safety programs aimed at addressing the needs of pediatric patients to enhance safe medication use.
\end{abstract}

\section{Keywords}

Medication Errors; Pediatrics; Healthcare 


\section{Introduction}

Medication errors have gained increasing attention as a national public health problem in the past 15 years $[1,2]$. Studies have estimated that approximately $5 \%$ of medication orders contain an error and half of these orders actually reach the patients $[3,4]$. Medication errors have resulted in approximately 7,000 deaths each year and 42,00o preventable adverse events in pediatrics [5].

In 1999, the Institute of Medicine published its first report "To Err is Human," with the attempt to shift the focus of preventing medication errors from the individual to the system and the establishment of a 50\% target in reducing errors [6]. In 2015, the Institute for Safe Medication Practices (ISMP) published a statement that affirmed that "more is needed to protect hospitalized children from medication errors [7].” They uncovered, through their survey of pediatric hospitals, the dearth of pediatric error prevention strategies. In fact, dose range checking, availability of clinical pharmacists inpatient care units, and independent double checks of high alert medications occurred in less than $65 \%$ of hospitals. The ISMP estimates that 1 in 10 children are impacted by a medication error and that up to $35 \%$ of these are serious or life-threatening. However other studies have suggested that $<1 \%$ of medication errors lead to adverse drug events [8]. Part of the ambiguity is due to various definitions of a medication error, sometimes referring to only prescribing errors or administration errors [5]. For hereon, medication error will be defined as, per the Institute of Medicine, "any error occurring in the drug-use process, or any preventable event that may cause or lead to inappropriate drug use or patient harm while the drug is in the control of the health care professional, patient or consumer [6]."

The trend towards developing and implementing interventions to safeguard the public has resulted in positive changes in healthcare; yet the epidemiology of the current errors, especially in pediatrics, and effectiveness of these interventions remain unclear $[3,9,10]$. Most research surrounding medication errors have been performed in adult hospitals, despite the fact that pediatric patients present unique challenges that are often overlooked [11]. Although medication error rates in pediatrics was reported to occur at similar rates as adults, pediatric patients are estimated to have three times the risk of potential adverse drug events. With the current adult-centric literature, a study that compares the prevalence and the specific types of medication errors between adults and pediatrics is the first step towards improved understanding of medication errors. As such, our primary objective was to compare the prevalence and types of medication errors that reached pediatric and adult patients during hospitalization.

\section{Patients and Methods}

\section{Study Design:}

This was an observational, non-experimental, cross-sectional study that compared the prevalence and types of medication errors between children and adults that occurred from January 2011 through March 2015 at Long Beach Memorial Hospital (LBMH) and Miller Children's \& Women's Hospital $(\mathrm{MCWH})$ in Long Beach. LBMH and MCWH are notfor-profit, community-based, tertiary care, teaching hospitals with a level 2 trauma center and 497 (61 intensive care) and 348 (137 intensive care) beds, respectively. They are both parts of the integrated MemorialCare Health System. All medication errors from $\mathrm{LBMH}$ were compared against all medication errors from MCWH. Notably, medication errors that occurred in the women's unit (i.e., part of MCWH) was incorporated as adult medication errors as they were not pediatric patients; thereby allowing us to truly evaluate the two distinct populations. Duplicate data were screened and excluded when identified. This study was approved by the institutional review boards with the use of a waiver of informed consent.

As part of routine care, medication errors were prospectively recorded and screened by two pharmacists who specialized in medication safety \& compliance for each hospital. All medication errors that reached patients were screened to ensure consistency and accuracy in describing the type of error and rating its severity. These data were extracted from Memsafe (which was both institutions' reporting system for unusual occurrences), Pharmacy OneSource, and antidote 
trigger reports generated from electronic medical records. Data were extracted into a de-identified Excel dataset for quarterly analysis and reporting to the hospital's Pharmacy and Therapeutics Committee.

\section{Definitions:}

To calculate the prevalence of medication errors, the total number of medication errors that reached the patient was divided per 10,00o medication orders. The same medication may have multiple orders for the same patient as each order distribution represents an opportunity for error. Drugs were classified using the American Hospital Formulary Service (AFHS) Pharmacologic-Therapeutic Classification.

The severity of the medication errors were scored based on the National Coordinating Council for Medication Error Reporting and Prevention (NCCMERP), with categories $\mathrm{C}$ to $\mathrm{D}$ defined as reaching the patient but not exhibiting any harm; $\mathrm{E}$ to $\mathrm{H}$ as exhibiting harm; and I as contributing to death [12]. Category A and B were not evaluated in this study since the potential errors were identified early in the medication use process and subsequently did not result in any medication error nor reached the patient. However, these categories A and B were assessed as safety interventions or "system catches" of potential medication errors. "System catches" were calculated using the medication errors identified without reaching the patient (Categories A-B) divided by the total number of errors identified (Categories A-I). In contrast, safety failures (i.e., termed "system passthroughs") of medication errors referred to the medications that were not caught and reached the patient. Unique to our hospitals, this format is used to report systems catches and pass-throughs quarterly to the Pharmacy and Therapeutics Committee.

\section{Descriptive Analysis:}

Statistical analyses were performed using SPSS for Windows version 22 (IBM, Chicago, Illinois). All statistical tests were performed using two-tailed analyses, and a $\mathrm{p}<0.05$ was considered significant for all evaluations. Data were summarized by mean \pm standard deviation (SD), or median with interquartile range for asymmetrically-distributed continuous variables (e.g., age); and numbers with percentages for categorical and ordinal data (e.g., severity, types of medication errors). Data were analyzed using appropriate tests, with missing values for each individual imputed using the last observation carried forward approach.

\section{Results}

The hospital census and doses dispensed for each hospital are provided in Table-1. Over the 4-year study period, there were 4.2 and 13.3 million doses dispensed in pediatrics and adults, respectively (Table-1). Less than $1 \%$ of doses dispensed contributed to medication errors, with 9.6\% (4,012 of 41,659 ) of medications reaching patients and $0.04 \%$ (157 of 41,659) causing harm. For pediatrics and adults over the study period, the percent of medication error "system catches" remained relatively steady (Fig-1A and Fig-1B). However, "system pass-throughs" in adults steadily increased from 2013 and 2015, perhaps due to an increase in

\begin{tabular}{|c|c|c|}
\hline \multicolumn{3}{|c|}{ Table-1: Hospital Census and Medication Errors } \\
\hline & Pediatrics & Adults \\
\hline Number of Admissions & 38,971 & $1,13,156$ \\
\hline Patient Days & $2,64,788$ & $5,81,935$ \\
\hline Doses Dispensed & $42,18,541$ & $1,32,80,156$ \\
\hline Total Beds & 348 & 497 \\
\hline Intensive Care Unit Beds & 137 & 61 \\
\hline Total Medication Errors & $6,281(0.15 \%)$ & $35,378(0.27 \%)$ \\
\hline Reached Patients & $1,213(19 \%)$ & $2,799(8 \%)$ \\
\hline Caused Patient Harm & $51(4.2 \%)$ & $106(3.8 \%)$ \\
\hline
\end{tabular}


Citation: Jimenez A, Tran TM, Le B, Le J. Comparative Cross-Sectional Pharmacovigilance Study of Medication Errors in Children and Adults in Community-Based Hospitals. Asp J Pediatrics Child Health. 2020 Jan 29;2(1):1-12.

\section{Original Article}

\section{Fig-1A: Pediatrics}

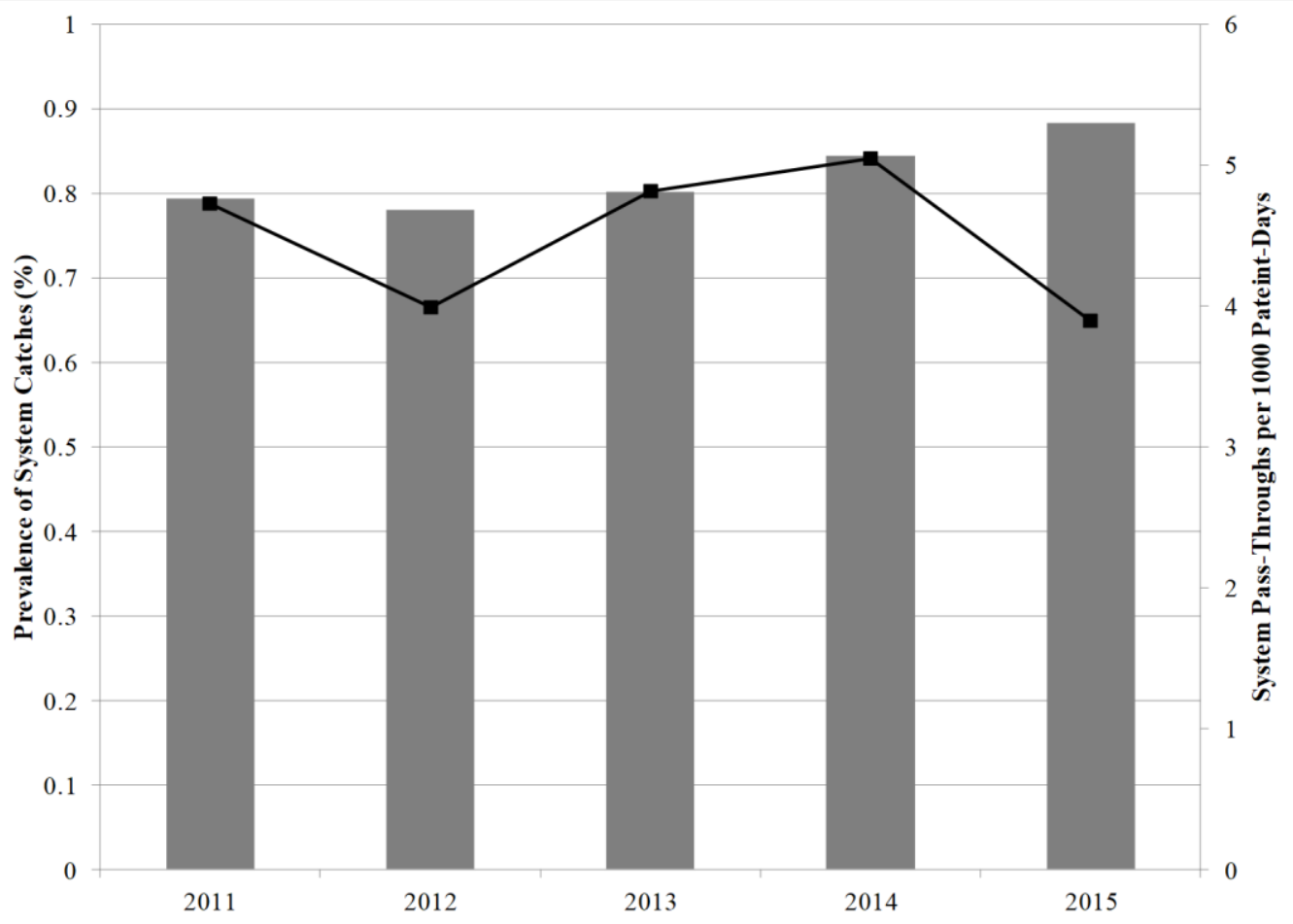

Grey bars represent "system catches" that were defined as the medications errors prevented without reaching the patient (NCC-MERP Categories A-B) and black line for "system pass-throughs," defined as medication errors that were not caught and reached the patient.

Fig-1B: Adults

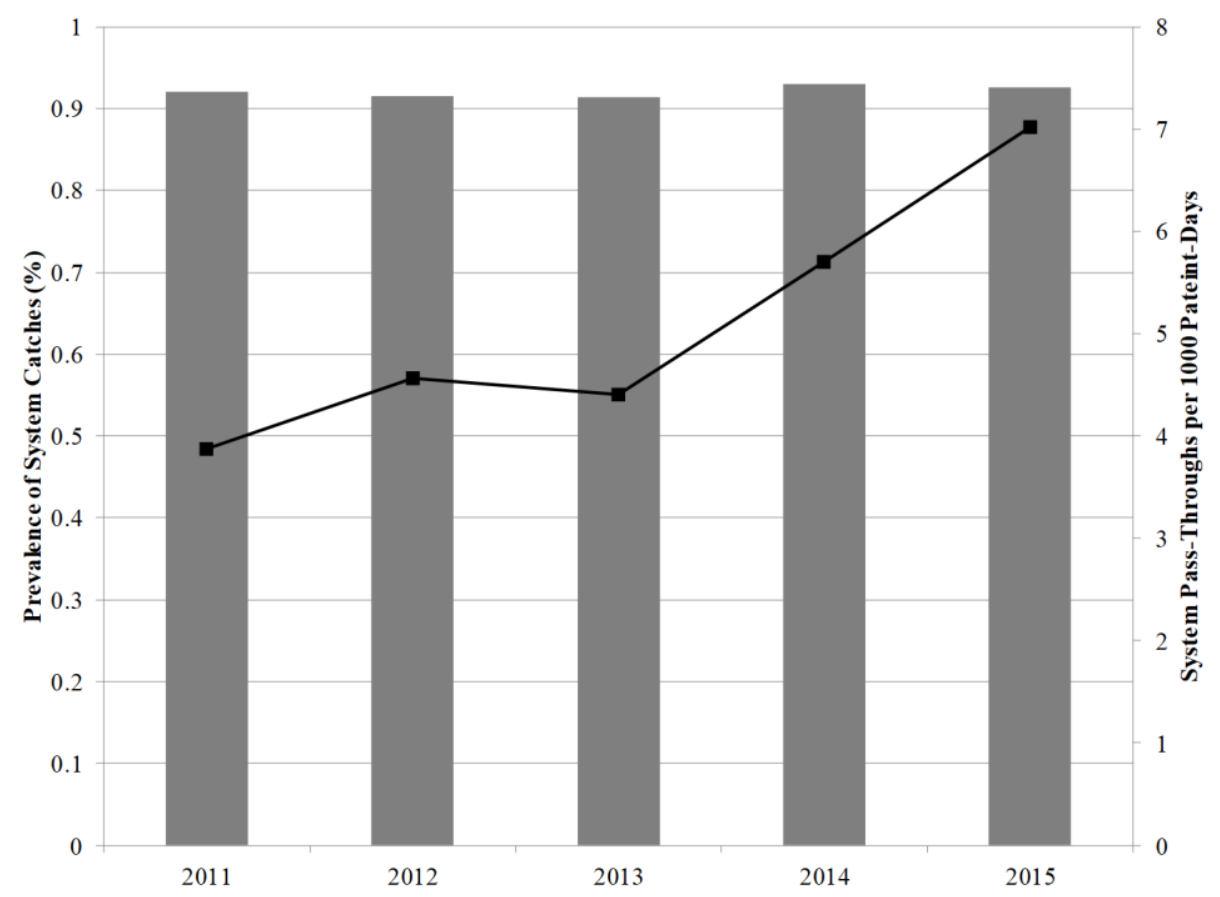

Grey bars represent "system catches" that were defined as the medications errors prevented without reaching the patient (NCC-MERP Categories A-B) and black line for "system pass-throughs," defined as medication errors that were not caught and reached the patient.

Fig-1: System Caught and Pass-Through Medication Errors over 5 Years 
identifying errors from barcode medication administration and patient scoring tools. For pediatric patients, "system pass-throughs" fluctuated, with an evident decrease in 2015 .

There was no statistical difference in medication errors that reached patients based on doses dispensed, patient-days, admission rate, and severity. However, based on the total number of medication errors, adults had significantly more errors than pediatrics (30.2\% of 860 vs $69.8 \%$ 2,709, respectively, $\mathrm{p}<0.001)$. Amongst those who experienced medication errors, stay in the intensive care unit (ICU) were higher in children than adults ( $41 \%$ vs $15 \%$, respectively, $\mathrm{p}<0.001$ ), perhaps due to the higher proportion of pediatric ICU beds (Table-1).

Using the AFHS classification, anti-infective agents were most associated with medication errors and the distribution of these drug classes were statistically varied between pediatrics and adults (Table-2). Children had higher rates of medication errors related to electrolytes and TPN, while adults had higher rates for anti-coagulation, cardiovascular, and hormones and synthetic drugs. Most medication errors did not cause harm (i.e., 95.8\% and 96.2\% in pediatrics and adults, respectively, had NCC-MERP Categories $\mathrm{C}$ to D). There were no statistical differences between the two groups in the prevalence of medication errors that caused harm (NCC-MERP Categories E to I, Table-2). Independent of age, there was significantly more medication errors that caused harm (i.e., NCC-MERP E-I) in patients residing in the ICU, as compared with those not in the ICU $(5.5 \%$ of 769 vs $3.5 \%$ of 2800 patients, respectively, $\mathrm{p}=0.006)$. The mean age was significantly lower for those located in versus not in the ICU $(35.7 \pm 32.4$ versus $50.2 \pm 26.4$ years, respectively, $\mathrm{p}<0.001)$. The healthcare professionals who were responsible for causing the medication errors were nurses, medical residents, pharmacists and physicians (Table-2).

Medication safety programs were implemented in attempt to decrease medication errors at both hospitals. These safety programs were unique to each hospital due to differing needs (i.e., populationspecific). A pharmacist-driven medication history and discharge process was initiated at LBMH, and Beacon, which was a pediatric oncology module within EPIC to streamline the safe use of chemotherapeutic agents, at MCWH (Fig-2A). There were no statistical differences between the two groups in the prevalence of medication errors, which may have been affected by these safety programs.

More errors in the documenting and prescribing process were observed in adults as compared with pediatrics (21.9 vs $6.5 \%$ and 37.4 vs $29.8 \%$, respectively, $\mathrm{p}<0.001$; Table-2). This trend was consistent when evaluated based on the total number of documented medication errors (Fig-2B). Specifically, in 2012, the adult hospital at LBMH initiated a medication history process where physicians were contacted directly for incorrect medication orders. This program was expanded in 2013 to incorporate the review and counseling of high-risk patients on discharge medications. During the implementation of these processes, LBMH experienced a surge in medication error reporting. Furthermore, in 2015, documentation errors were redefined as prescribing errors and categorized these errors during admission and discharge to increase physician awareness.

In contrast, there were significantly more errors identified in the administering process for pediatrics than adults (42.5 vs $29.8 \%$ in adults, p < 0.001 ; Table-2). Using the number of medication errors that occurred during administration, the medication errors per 100,000 doses dispensed were consistently higher in pediatrics than adults each year during the study period (Fig-2C). In pediatrics, the administration errors consisted most commonly of infusion devices, incorrect dose, omission of medication, and time of administration (Fig-3). During that time, MCWH implemented specific interventions targeting such errors. In 2012, infusion pumps and patient-controlled analgesic smart pumps were updated. In addition to already being mandatory for nurses to use the pumps with a 2-person dual verification for high-risk meds, an annual nursing skills day for nurses to obtain hands-on teaching was initiated. Patient-specific barcoded doses were also initiated to decrease administration error. By 2014, 
Citation: Jimenez A, Tran TM, Le B, Le J. Comparative Cross-Sectional Pharmacovigilance Study of Medication Errors in Children and Adults in Community-Based Hospitals. Asp J Pediatrics Child Health. 2020 Jan 29;2(1):1-12.

\section{Original Article}

Table-2: Demographics, Prevalence, Types and Classification of Medication Errors that Reached Patients

\begin{tabular}{|c|c|c|c|}
\hline & Pediatrics & Adults & p-value \\
\hline & $\mathrm{n}=1, \mathbf{2 1 3}$ & $\mathrm{n}=2,799$ & \\
\hline \multicolumn{4}{|l|}{ Demographics } \\
\hline Mean Age ( \pm Standard Deviation, years) & $7 \cdot 0 \pm 7 \cdot 3$ & $59 \cdot 9 \pm 19 \cdot 3$ & $<0.001$ \\
\hline Male Gender & $447(52 \%)$ & $1517(56 \%)$ & 0.002 \\
\hline Intensive Care Unit & $353(41 \%)$ & $406(15 \%)$ & $<0.001$ \\
\hline \multicolumn{4}{|l|}{ Error Rates } \\
\hline Per 10,000 Doses Dispensed & 2.9 & 2.1 & 1 \\
\hline Per 1,ooo Patient Days & 4.6 & 4.8 & 0.568 \\
\hline Per 1,00o Admissions & 31.1 & $24 \cdot 7$ & 0.269 \\
\hline Per Total Errors & 30.2 & 69.8 & $<0.001$ \\
\hline \multicolumn{4}{|l|}{ Medication Use Process } \\
\hline Prescribing & $361(29.8 \%)$ & $1047(37.4 \%)$ & \multirow{5}{*}{$<0.001$} \\
\hline Administration & $516(42.5 \%)$ & $834(29.8 \%)$ & \\
\hline Documentation & $79(6.5 \%)$ & $613(21.9 \%)$ & \\
\hline Dispensing & $163(13.4 \%)$ & $151(5.4 \%)$ & \\
\hline Monitoring & $67(5.5 \%)$ & $140(5 \%)$ & \\
\hline \multicolumn{4}{|c|}{ American Hospital Formulary Service (AFHS) Pharmacologic-Therapeutic Classification } \\
\hline Anti-Infective & $328(27 \%)$ & $644(23 \%)$ & $<0.007$ \\
\hline Central Nervous System & $210(17 \cdot 3 \%)$ & $551(19.7 \%)$ & \multirow{6}{*}{$<0.001$} \\
\hline Electrolytes \& Total Parenteral Nutrition & $241(19.9 \%)$ & $232(8.3 \%)$ & \\
\hline Cardiovascular & $59(4 \cdot 9 \%)$ & $350(12.5 \%)$ & \\
\hline Hormones and Synthetic & $80(6.6 \%)$ & $294(10.5 \%)$ & \\
\hline Anti-Coagulation & $29(2.4 \%)$ & $319(11.4 \%)$ & \\
\hline Other & $266(21.9 \%)$ & $409(14.6 \%)$ & \\
\hline \multicolumn{4}{|c|}{$\begin{array}{l}\text { Severity Categories by the National Coordinating Council for Medication Error Reporting and Prevention (NCC- } \\
M E R P)^{a}\end{array}$} \\
\hline $\mathrm{C}$ & $792(65 \cdot 3)$ & $1954(69.8)$ & 0.004 \\
\hline $\mathrm{D}$ & $370(30.5)$ & $739(26.4)$ & 0.007 \\
\hline $\mathrm{E}$ & $47(3.9)$ & $98(3.5)$ & $<0.001$ \\
\hline $\mathrm{F}$ & $4(0.3)$ & $6(0.2)$ & $<0.001$ \\
\hline \multicolumn{4}{|c|}{ Healthcare Professional Responsible for Causing Medication Errors } \\
\hline Nurse & $582(48)$ & $1427(51)$ & \multirow{5}{*}{$-{ }^{b}$} \\
\hline Medical Resident & $279(23)$ & $924(33)$ & \\
\hline Pharmacist & $291(24)$ & $364(13)$ & \\
\hline Physician & $36(3)$ & $28(1)$ & \\
\hline Other & $24(2)$ & $56(2)$ & \\
\hline
\end{tabular}

${ }^{\mathrm{a}}$ The prevalence of categories $\mathrm{G}$ to I was zero, except for $0.1 \%$ of category $\mathrm{H}$ in adults.

${ }^{\mathrm{b}} \mathrm{P}$-values were not determined since reporting is for descriptive purpose 
Citation: Jimenez A, Tran TM, Le B, Le J. Comparative Cross-Sectional Pharmacovigilance Study of Medication Errors in Children and Adults in Community-Based Hospitals. Asp J Pediatrics Child Health. 2020 Jan 29;2(1):1-12.

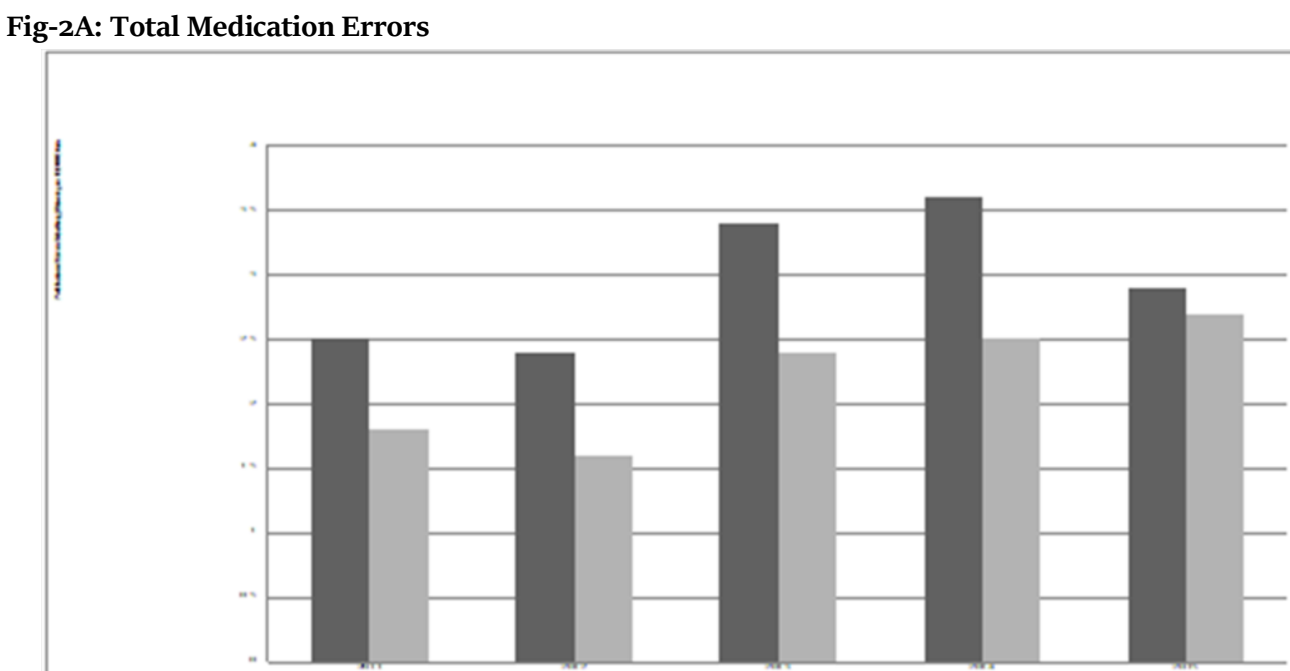

- Beacon (Pediatric Oncology)

- Medication Histories (Adults)

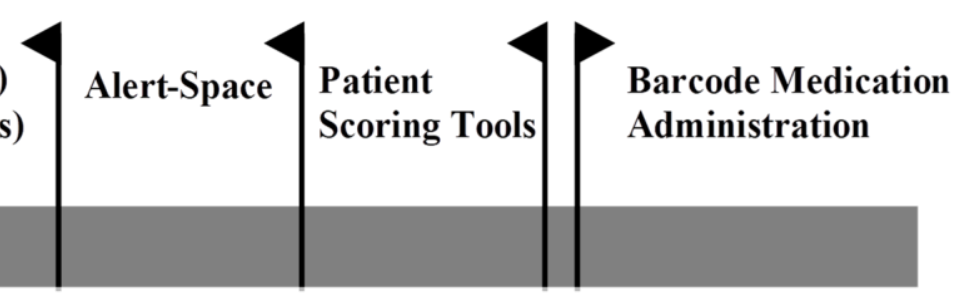

Fig-2B: Documentation Errors

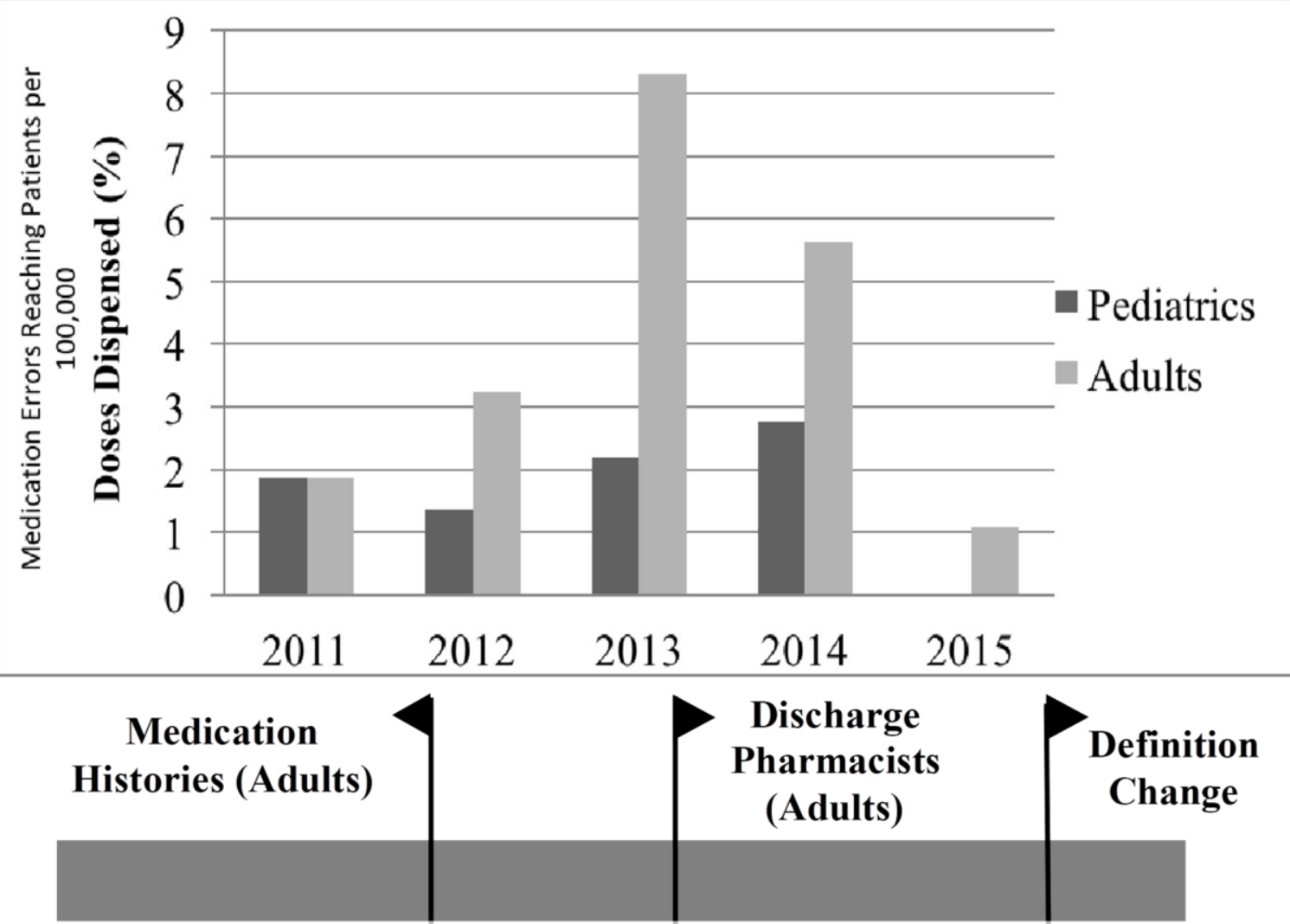


Citation: Jimenez A, Tran TM, Le B, Le J. Comparative Cross-Sectional Pharmacovigilance Study of Medication Errors in Children and Adults in Community-Based Hospitals. Asp J Pediatrics Child Health. 2020 Jan 29;2(1):1-12.

\section{Original Article}

Fig-2C: Administration Errors
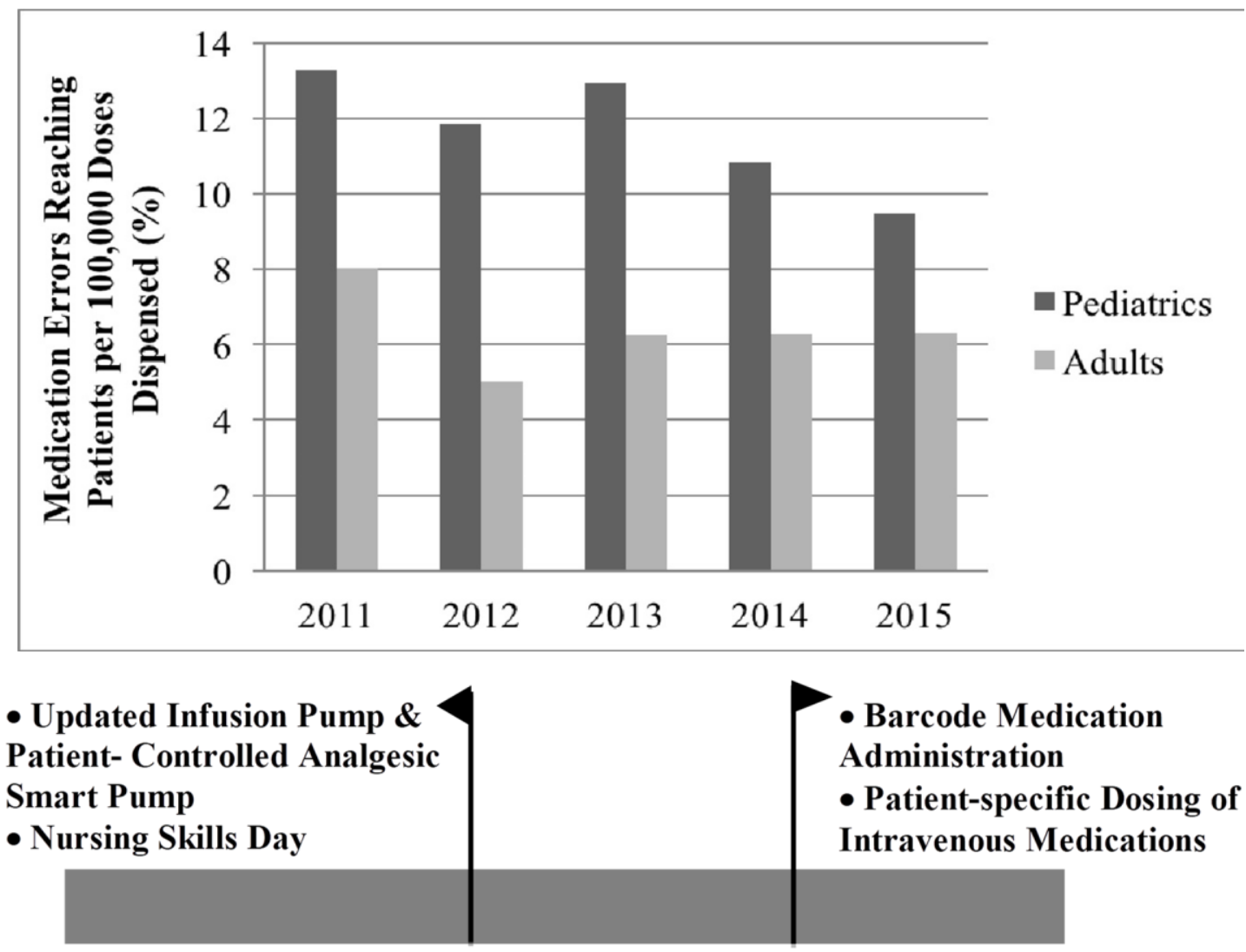

Fig- 2: Medication Errors by Year Based on Changes in the Medication Use Process

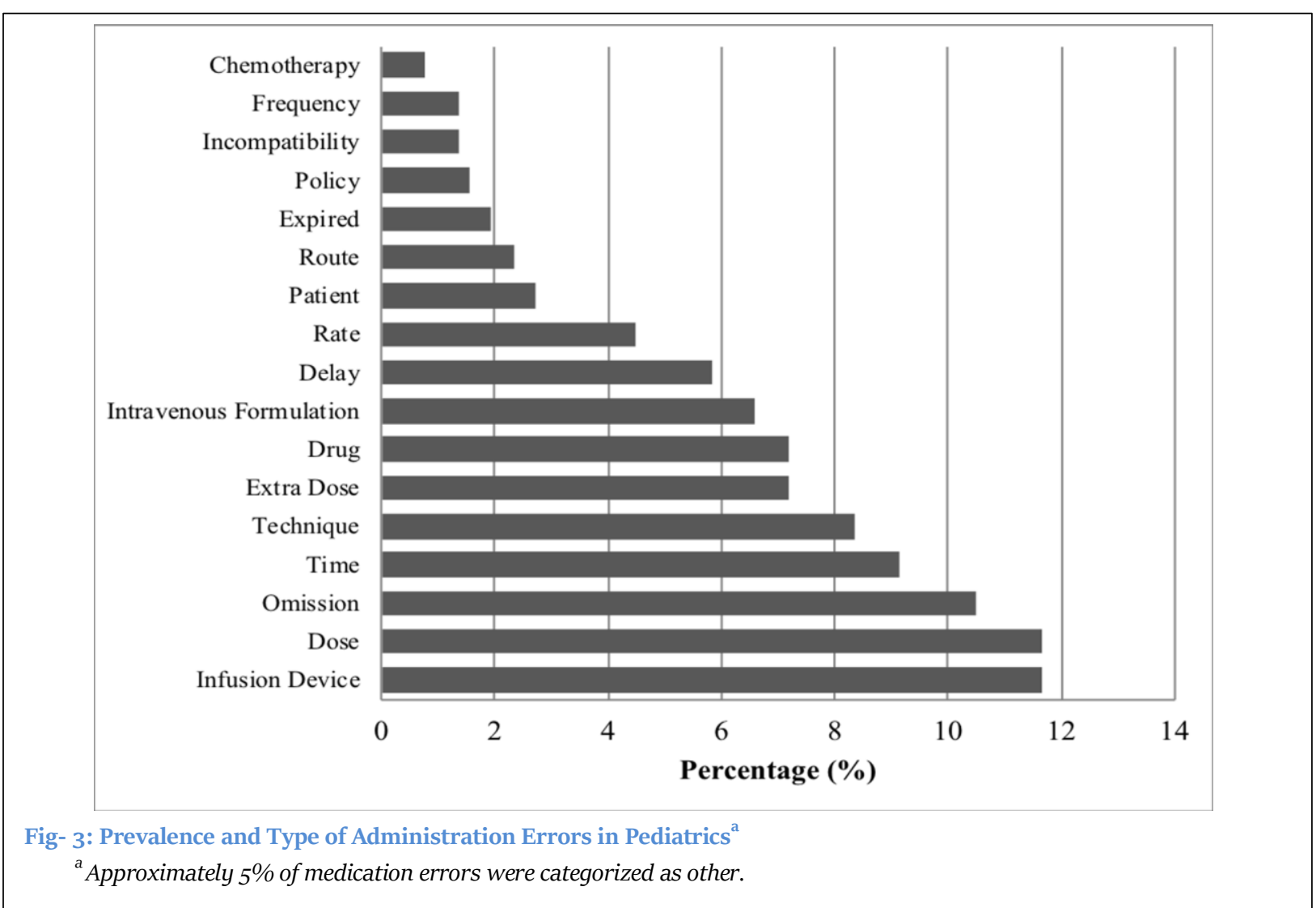


almost all medication dosages were patient-specific and nurses were required to use barcode medication administration to verify all medication prior to administration.

\section{Discussion}

Medical care (which encompasses medication use) in pediatrics in the United States occurs mainly in adult hospitals with adult medication-use infrastructure [13]. While 90\% of these hospitals employ computerized physician order entry for dosing medications in pediatrics, five critical gaps were identified: lack of documenting dosages in $\mathrm{mg} / \mathrm{kg}$, maximum dose alert, pediatric-specific medication safety committee, pediatric pharmacists, and weight-based dosing in the emergency department. This leaves pediatric patients vulnerable to a plethora of potential problems. Unique in our study was the comparative analysis of the prevalence and types of medication errors between pediatric and adult populations within the same health system. Since medication error rates are difficult to compare between hospitals with their distinct systems and cultures, we leveraged our two pediatric and adult hospitals with similar structures and values in the medication use process.

Our pediatricians, adult physicians, and pharmacists at both hospitals, together and with the Pharmacy and Therapeutics Committee, work very closely to ensure the accuracy of reporting and preventing medication errors. At $\mathrm{MCWH}$, the pediatric medication safety committee also provides another structural level to ensure patient safety. We require $\mathrm{mg} / \mathrm{kg}$ documentation in the hospital (including the emergency department), and dose range alerts. Furthermore, our physicians and pharmacists, who are key players to the operational aspect of medication ordering and management, were vital in designing a computerized system with an intelligent build to prevent medication errors.

In our study, $<1 \%$ of doses dispensed contributed to medication errors, with $9.6 \%$ of medication errors reaching patients and $0.04 \%$ causing harm. This is significantly less than the ISMP estimate of $10 \%$ of children impacted by a medication error and $35 \%$ of those errors being life threatening [7]. The low prevalence of medication errors in our study may perhaps be explained by the proactive involvement of healthcare professionals in designing the medication use system.

Based on three pediatric studies conducted in the United States, the prevalence of medication errors per orders have ranged from 5 to $27 \%[4,14,15]$. Notably, we selectively and intentionally evaluated the prevalence of medication errors by doses dispensed (rather than by order), as each dose that is dispensed represents an opportunity for error. Using the total of doses dispensed, rather than medication orders, provides a more realistic and complete account of true errors that occurred. Although one study compared the rates of pediatric medication errors to previously reported adult rates, there have been no studies that directly compared medication errors, especially those that reached the patients, in adults and pediatrics [4].

Anti-infective agents were most commonly associated with medication errors in both our pediatric and adult patients, accounting for approximately $25 \%$ of total medication errors. This is a finding consistent with published studies [16,17]. Anti-infective agents also have been reported to contribute to adverse drug reactions, albeit they were usually mild in severity [18]. Electrolytes and TPN also resulted in more medication errors in pediatrics than adults, making this a class of drugs that requires heightened vigilance in children.

We described the trend of medication errors over time to enhance our understanding of errors relative to the implementation of various medication safety programs that may have affected the detection and reporting of medication errors. There were more medication errors identified in adults for the documentation and prescribing processes, likely due to the addition of medication history and discharge education. One study demonstrated a $52 \%$ reduction in medication discrepancies with the addition of medication reconciliation at discharge [19]. Medication reconciliation appears to be a useful method to reduce medication errors, particularly during transitions of care [19-22]. 
There were more medication errors identified in pediatrics for drug administration, possibly due to the increased range of medication concentrations and formulations required to care for this population, from neonates to adolescents. Many high-risk sedation and pain medications are used in pumps which can be inputted incorrectly leading to 10- to 100-fold in errors. One study demonstrated that a two-person verification approach reduced medication errors related to pumps without delaying care [23]. At MCWH, we also utilize this two-person verification, yet still encountered incorrect medication selection and alert overrides on the pumps. In addition, common medication errors in pediatric patients have been attributed to unique dosage formulations and compounded medications, along with inappropriate weight-based dosing and high usage of off-label medications [24-27]. A recent systematic review identified 26 strategies to reduce medication errors; notably, none were based on pediatric-specific evidence [11]. Another recent metaanalysis evaluated five different interventions (including computerized physician order entry, barcode medication administration, prescribing forms, and checklists) to reduce medication errors in hospitalized children [10]. Interestingly, this study concluded that none of the interventions resulted in a significant reduction in patient harm, perhaps contributed by the lack of robust studies to incorporate the pediatric elements.

Most medication errors in our study were classified as NCC-MERP categories C and D, indicating minimal harm to the patients. Compared with adults, pediatrics had a higher prevalence of category D that required monitoring and/or intervention to preclude harm. The differences in physiologic maturation with age and sensitivity to medications may have contributed to the need for enhanced monitoring and/or intervention. Furthermore, unique to pediatrics is the higher distribution of medications in the intensive care unit in pediatrics, as compared with adults. This warrants further exploration.

There were several limitations to our study. All medication error rates were determined by compliance with the reporting of errors that were dictated by clinical judgment. In addition, the changes in the prevalence of errors may have been contributed by compliance with the different reporting requirement and implementation of additional safeguards, which differed between the two hospitals. Pharmacists are expected to report all medication errors, especially if they reached patients, in the pediatric hospital, whereas only a minimum of two medication errors per pharmacist work shift is required in the adult hospital. Lastly, well newborn babies were sometimes kept in the mother's room, so their medications (albeit few) were categorized under the adult denominator.

\section{Conclusion}

While we report similarity in the prevalence of medication errors that reached patients and that caused harm, the types of errors within the medication use process, class of drugs, and severity of the mediation errors varied between pediatrics and adults. The implementation of medication safety programs to meet the needs of the service population may have contributed to our study findings. Population-specific medication safety programs are crucial for pediatrics since they have distinct physiologic handling, response, and sensitivity to drugs, coupled to additional challenges related to the wide age spectrum (i.e., increased dosage formulations and availability of different concentrations). Future studies should explore specific populations, drugs, and medication use processes that contribute to the greatest risk of medication errors (including, ICU stay, anti-infective agents, and administration in pediatrics, respectively). More importantly, studies are needed to elucidate medication safety interventions that can effectively prevent medication errors and ultimately, patient harm.

\section{Acknowledgments}

We sincerely thank Lisa Veal, PharmD (associated with Miller Children's and Women's Hospital) and Linda Bui, PharmD (associated with Long Beach Memorial Hospital) for providing the de-identified data that were crucial to successfully complete this study; and Jeffrey Qui (associated with the University of California, San Diego) for reviewing and formatting our manuscript. 
This study was not supported by any funding agency. The authors are solely responsible for the study design, data collection, and analysis, decision to publish, or preparation of the manuscript.

\section{Financial Disclosure}

The authors have no financial relationships relevant to this article to disclose.

\section{Funding Source}

This project has no funding source relevant to this article to disclose.

\section{Conflicts of Interest}

The authors have no conflicts of interest relevant to this article to disclose.

\section{Contributor's Statement}

Dr. Wong conceptualized and designed the study, designed the collection instruments, collected the data, co-drafted the initial manuscript, revised the manuscript, and approved the final manuscript as submitted.

Mr. Tran assisted in the design of the study, data analysis, drafting the initial manuscript, revised the manuscript, and approved the final manuscript as submitted.

Mr. Le assisted in the data analysis, drafting the initial manuscript, revised the manuscript, and approved the final manuscript as submitted.

Dr. Le conceptualized and designed the study, conducted the data analysis, co-drafted the initial manuscript, revised the manuscript, and approved the final manuscript as submitted.

All authors approved the final manuscript as submitted and agree to be accountable for all aspects of the work.

\section{References}

[1] Fortescue EB, Kaushal R, Landrigan CP, McKenna KJ, Clapp MD, Federico F, Goldmann DA, Bates DW.
Prioritizing strategies for preventing medication errors and adverse drug events in pediatric inpatients. Pediatrics. 2003 Apr;111(4 Pt 1):722-29. [PMID: 12671103]

[2] Smyth RM, Gargon E, Kirkham J, Cresswell L, Golder S, Smyth R, Williamson P. Adverse drug reactions in children--a systematic review. PLoS One. 2012;7(3):e24061. [PMID: 22403604]

[3] Kuo GM, Touchette DR, Marinac JS. Drug errors and related interventions reported by United States clinical pharmacists: the American College of Clinical Pharmacy practice-based research network medication error detection, amelioration and prevention study. Pharmacotherapy. 2013 Mar;33(3):253-65. [PMID: 23378169]

[4] Kaushal R, Bates DW, Landrigan C, McKenna KJ, Clapp MD, Federico F, Goldmann DA. Medication errors and adverse drug events in pediatric inpatients. JAMA. 2001 Apr 25;285(16):2114-20. [PMID: 11311101] [5] Leonard MS. Patient safety and quality improvement: medical errors and adverse events. Pediatr Rev. 2010 Apr;31(4):151-58. [PMID:
[P 20360409]

[6] Kohn LT, Corrigan J, Donaldson MS. To err is human: building a safer health system. Washington, DC: National academy press; 2000 Apr.

[7] Institute for Safe Medication Practices. Results of Survey on Pediatric Medication Safety (Part 1): More is Needed to Protect Hospitalized Children from Medication Errors. 2015 Jun 4.

[8] Stucky ER; American Academy of Pediatrics Committee on Drugs; American Academy of Pediatrics Committee on Hospital Care. Prevention of medication errors in the pediatric inpatient setting. Pediatrics. 2003 Aug;112(2):431-36. [PMID: 12897304]

[9] Garner SS, Cox TH, Hill EG, Irving MG, Bissinger RL, Annibale DJ. Prospective, controlled study of an intervention to reduce errors in neonatal antibiotic orders. J Perinatol. 2015 Aug;35(8):631-35. [PMID: 25836318]

[10] Maaskant JM, Vermeulen H, Apampa B, Fernando B, Ghaleb MA, Neubert A, Thayyil S, Soe A. Interventions for reducing medication errors in children in hospital. Cochrane Database of Systematic Reviews. 2015 Mar 10(3):CDoo6208.

[11] Miller MR, Robinson KA, Lubomski LH, Rinke ML, Pronovost PJ. Medication errors in paediatric care: a 
systematic review of epidemiology and an evaluation of evidence supporting reduction strategy recommendations. Qual Saf Health Care. 2007 Apr;16(2):116-26. [PMID: 17403758]

[12] National Coordinating Council for Medication Error Reporting and Prevention. [cited 2017 April 5]; Available from: http://www.nccmerp.org/typesmedication-errors

[13] Alvarez F, Ismail L, Markowsky A. Pediatric Medication Safety in Adult Community Hospital Settings: A Glimpse Into Nationwide Practice. Hosp Pediatr. 2016 Dec;6(12):744-49. [PMID: 27811162]

[14] Marino BL, Reinhardt K, Eichelberger WJ, Steingard R. Prevalence of errors in a pediatric hospital medication system: implications for error proofing. Outcomes Manag Nurs Pract. 2000 JulSep;4(3):129-35. [PMID: 11299582]

[15] Cimino MA, Kirschbaum MS, Brodsky L, Shaha $\mathrm{SH}$; Child Health Accountability Initiative. Assessing medication prescribing errors in pediatric intensive care units. Pediatr Crit Care Med. 2004 Mar;5(2):124-32. [PMID: 14987341]

[16] Zakharov S, Tomas N, Pelclova D. Medication errors-an enduring problem for children and elderly patients. Ups J Med Sci. 2012 Aug;117(3):309-17. [PMID: 22376241]

[17] Glanzmann C, Frey B, Meier CR, Vonbach P. Analysis of medication prescribing errors in critically ill children. Eur J Pediatr. 2015 Oct;174(10):1347-55. [PMID: 25899070]

[18] Le J, Nguyen T, Law AV, Hodding J. Adverse drug reactions among children over a 10-year period. Pediatrics. 2006 Aug;118(2):555-62. [PMID: 16882807]

[19] Najafzadeh M, Schnipper JL, Shrank WH, Kymes S, Brennan TA, Choudhry NK. Economic value of pharmacist-led medication reconciliation for reducing medication errors after hospital discharge. Am J Manag Care. 2016 Oct;22(10):654-61. [PMID: 28557517]

[20] Mueller SK, Sponsler KC, Kripalani S, Schnipper JL. Hospital-based medication reconciliation practices: a systematic review. Arch Intern Med. 2012 Jul 23;172(14):1057-69. [PMID: 22733210]

[21] Lehnbom EC, Stewart MJ, Manias E, Westbrook
JI. Impact of medication reconciliation and review on clinical outcomes. Ann Pharmacother. 2014 Oct;48(10):1298-12. [PMID: 25048794]

[22] Moro Agud M, Menéndez Colino R, Mauleón Ladrero Mdel C, Ruano Encinar M, Díez Sebastián J, Villamañán Bueno E, Herrero Ambrosio A, González Montalvo JI. Analysis of an electronic medication reconciliation and information at discharge programme for frail elderly patients. Int J Clin Pharm. 2016 Aug;38(4):996-1001. [PMID: 27306652]

[23] Subramanyam R, Mahmoud M, Buck D, Varughese A. Infusion Medication Error Reduction by Two-Person Verification: A Quality Improvement Initiative. Pediatrics. 2016 Dec;138(6). pii: e20154413. [PMID: 27940663]

[24] Impicciatore P, Choonara I, Clarkson A, Provasi D, Pandolfini C, Bonati M. Incidence of adverse drug reactions in paediatric in/out-patients: a systematic review and meta-analysis of prospective studies. $\mathrm{Br} \mathrm{J}$ Clin Pharmacol. 2001 Jul;52(1):77-83. [PMID: 11453893]

[25] Ghaleb MA, Barber N, Franklin BD, Yeung VW, Khaki ZF, Wong IC. Systematic review of medication errors in pediatric patients. Ann Pharmacother. 2006 Oct;4O(10):1766-76. [PMID: 16985096]

[26] Gallagher RM, Bird KA, Mason JR, Peak M, Williamson PR, Nunn AJ, Turner MA, Pirmohamed M, Smyth RL. Adverse drug reactions causing admission to a paediatric hospital: a pilot study. J Clin Pharm Ther. 2011 Apr;36(2):194-99. [PMID: 21366649]

[27] Preventable Deaths by 2020. Actionable Patient Safety Solution (APSS) \# 2: Medication Errors. January 8, 2014. Available at:

http://patientsafetymovement.org/wpcontent/uploads/2016/o2/APSS-3ABCD_-MedicationErrors.pdf. Accessed: April 21, 2017. 